\title{
ESPACIO BIOGRÁFICO EN DURMIENTES DE SARA ROSENBERG
}

\author{
Isabel Araoz \\ UNT- IIELA-CONICET
}

Resumen: El presente trabajo tiene el propósito de indagar la construcción narrativa del "espacio biográfico" (Arfuch, 2007) en el libro Durmientes de la escritora argentina Sara Rosenberg, recientemente publicado por una editorial cartonera. Lo biográfico es entendido en el cruce de lo público y lo privado, de la historia y la memoria, en la mixtura de los géneros (diario de viaje, ensayo, poesía). El viaje representado como la búsqueda de un yo, desplazado (exiliado) que construye su propia versión del mapa de una ciudad o de una nación devastada a la que es imposible volver.

Palabras claves: espacio biográfico- viaje- Sara Rosenberg.

\begin{abstract}
The present work has the intention of investigating the narrative construction of the "biographical space" in the book Durmientes by the Argentine writer Sara Rosenberg, recently published for a cartonera publishing house. The biographical issue is understood in the crossing of the public and the private, of the history and the memory, in the mixture of the genres (travel journal, essay, the poetry). The trip represented as the search of an ego, displaced (in exile) who constructs his own version of the map of a city or of a nation devastated to which is impossible to return.
\end{abstract}

Key words: biographical space- the trip- Sara Rosenberg.

$N^{\circ}$ 2. Segundo semestre de 2014 


\section{Introducción}

La producción artística y literaria de Sara Rosenberg (1954) puede ser entendida como un caso emblemático de una poética "fuera de lugar", dado que se configura en un espacio desterritorializado - entendido en sus diversos matices de exilio, desplazamiento, extranjería- desde donde disputa las narraciones alrededor de la identidad, el territorio y la lengua (Speranza, 2012). Rosenberg explora los diferentes lenguajes de la palabra, la imagen, el sonido, la textura: desde fines de la década del ochenta participa en muestras e instalaciones de arte, de un lado y del otro del Atlántico (España-Argentina); es dramaturga y directora de teatro y sus obras se han publicado en Italia y Francia. Desde su primer libro, Un bilo rojo (1998), las editoriales españolas dieron a conocer sus novelasCuadernos de invierno (Espase Calpe, 2000), La edad de barro (Destinos, 2003) y Contraluz (Siruela, 2008). Sin embargo, la incipiente obra literaria de Rosenberg no lograba atravesar el océano, hasta que en 2013 "El Cruce Cartonero" de Tucumán ${ }^{1}$ reeditara su novela prima junto a Durmientes. Apuntes de viaje.

En el caso de su novelística, el destierro se tematiza como una experiencia radical; los protagonistas de sus novelas son sujetos cuya identidad está escindida, quebrada o anulada,

\footnotetext{
${ }^{1}$ El estudio de Jaime Vargas Luna (2009) ilumina algunos aspectos para entender el "fenómeno cartonero" en la Argentina; las editoriales cartoneras (como una posible variante de las denominadas "independientes"), a diferencia de las industrias convencionales del libro (hoy, multinacionales), poseen otros criterios de sostenibilidad: trabajo voluntario no remunerado, tirajes mínimos, sistema de impresión artesanal bajo demanda, reducción de costos gracias a subvenciones (estatales o privadas) y un radio de acción menor (en cuanto a número de lectores y circuitos de circulación). Véase: Luna, J. V. (2009). "La rumba y el rumbo: editoriales cartoneras y edición independiente en Latinoamérica". En AAVV, Akademia Cartonera: un ABC de las editoriales cartoneras en Latinoamérica (págs. 111-129). Wisconsin: Parallel.
} 
en el desplazamiento incesante entre las geografías de un "aquî" y de un "allá" que enfatizan la idea de un "no lugar". Toda la producción de Rosenberg está atravesada por el exilio y está ligada al compromiso ético con y desde el arte. En Durmientes se hace palpable esa errancia, la exploración por la escritura y la imagen, la mixtura de los géneros que confluyen (el diario, el poema, el testimonio, la crónica, etc.) y que proponen al lector un pacto de lectura doble, híbrido, en la frontera de lo real y lo ficticio. 


\section{Espacio biográfico y desplazamiento}

Philippe Lejeune en su ya clásico estudio El pacto autobiográfico (1975) aborda la compleja frontera entre los géneros "ficticios" y "factuales" con el propósito de definir el estatuto de la autobiografía. La presencia de lo biográfico nos enfrenta con un problema crucial: si su escritura se construye sobre la base de los datos exteriores al texto, la autobiografía exigiría un conocimiento sobre esa "realidad verificable" que le otorga sustento a la identificación- "al nombre propio"- del autor, el narrador y el protagonista. Lejeune la define, en un primer momento, como "un relato retrospectivo en prosa que una persona real hace de su propia existencia poniendo énfasis en su vida individual y en particular, en la historia de su personalidad" (1994, p. 50). Ese "nombre propio o identidad" aparece como la "firma" de lo que llamamos autor, es decir, la marca en el texto de un mundo extratextual indudable, puesto que nos reenvía a una persona real socialmente responsable, que produce un discurso. Ahora bien, el lector establece un "pacto autobiográfico", un contrato de identidad sellado por aquel que escribe el texto, en tanto género "referencial" construye un "efecto de realidad" que es establecido y mantenido por el lector, quien crea un "espacio autobiográfico" (Lejeune, 1994 p. 83). Por su parte, José María Pozuelo Yvancos (2006) piensa el carácter fronterizo de la autobiografía desde una concepción dual, en el límite entre la construcción de una identidad con elementos de invención y la relación de numerosos hechos que se testimonian como reales; alrededor de ella se discuten otros problemas como la lucha entre la ficción y la verdad, la referencialidad, la cuestión del 
sujeto y la narratividad como construcción del mundo. En este sentido, y sin perder de vista una perspectiva histórica del género- "multiforme", "convencional" y "movedizo"- podemos decir que se trata de una "autoexhibición de la individualidad" y de una "autojustificación" por medio de la escritura. José Amícola, por su parte, realiza algunas observaciones interesantes: una, que a pesar de la pretensión de diferenciar la autobiografía de otros géneros afines ${ }^{2}$, emergen formas híbridas que problematizan su clasificación; dos, que oscila entre la certeza y la incertidumbre, pero además, en el simulacro de que lo narrado es lo vivido, impide percibir la dimensión de lo silenciado o lo olvidado; tres, es necesario entenderla como un "acto performativo" puesto que a medida que el sujeto se escribe, se construye como tal. El crítico advierte que no es posible hablar de una identificación total entre autor real y enunciador, sino más bien, de una identidad establecida pragmáticamente, que no borra las tensiones entre lo uno y lo múltiple, así como tampoco entre aquello que se ha vivido y los modos de representarlo. Por último, la autobiografía articula la recuperación del pasado, el drama del individuo por restaurar sus despojos y reconocer el carácter singular de sí mismo en un momento de la historia, y la intención de conmover a su lector con la narración de su vida.

La noción más flexible de "lo biográfico" permite entrever un universo amplio de géneros discursivos que se proponen capturar la cualidad efímera de la vida y las singularidades de los acontecimientos; la escritura se convierte en el

\footnotetext{
${ }^{2}$ Géneros como las memorias, las confesiones, los diarios íntimos la biografía, los recuerdos de infancia (Rosa Chancel 1990, citado por Amícola, 2007).

$N^{\circ}$ 2. Segundo semestre de 2014
} 
gesto insistente de guardar en la memoria huellas, rastros e imágenes. Para nuestra lectura de Durmientes, el término de "espacio biográfico" de Leonor Arfuch (2002) se presenta como el más adecuado, puesto que privilegia la heterogeneidad y la hibridación de los géneros, la intertextualidad, la mutación del yo que inscribe su singularidad, entre otros aspectos, que podemos reconocer en la escritura de Sara Rosenberg. Este concepto se define como una manera de "contar una experiencia de vida" (Arfuch, 2002, p. 87), que se articula "narrativamente" y que presenta ciertos procedimientos compositivos característicos; el espacio biográfico construye una "identidad narrativa" - la autora retoma la propuesta de Paul Ricoeur- que puede ocupar diferentes posiciones en relación con las diversas formas de asunción del yo (Arfuch, 2002, p. 28). El espacio biográfico enlaza el mundo de lo íntimo, lo privado y lo público, porque "todo relato de la experiencia es, en un punto, colectiva/o, experiencia de una época, de un grupo, de una generación, de una clase..." (Arfuch, 2002, p. 79). "El espacio de la vida narrada" encuentra puntos de contacto con el "cronotopo" bajtiniano (Teoría y estética de la novela 1989), que supone la interrelación de las coordenadas de espacio y tiempo. El lector podrá observar en Durmientes una serie de "micro-cronotopos" incluidos: el primero de ellos, el viaje en tren que se cuenta desde dentro de sus vagones y el recorrido (espacio-temporal) a través del territorio nacional desde Buenos Aires hasta Tucumán. El segundo, el cuerpo que se expresa por medio de los recuerdos que se despiertan y de las sensaciones que experimenta en este itinerario por tierra. De esa manera, los espacios de lo público, lo privado y lo 
íntimo se estrechan aún más por medio de la narración, alrededor de un yo. Ese desplazamiento identitario que se produce en el relato está ligado a la experiencia del exilio de la autora, del regreso a la casa (y a la madre) y puede ser leído como un caso para-digmático que revela el "carácter migrante de toda identidad" (Arfuch, 2002, p. 31).

El movimiento ("del afuera hacia adentro") por medio de la escritura al que apela Rosenberg habilita la pregunta de cuál es el lugar de la autora en "el cuerpo deforme e imaginario de la literatura argentina”, cómo su experiencia diaspórica incide en su poética y señala una tensión entre la inscripción y la exclusión de una "literatura nacional" (Molloy, 2006, p.9) y por último, cómo la experiencia del desplazamiento se convierte en un lugar complejo y precario de enunciación, pero que, al mismo tiempo, le permite asumir múltiples matices y valoraciones que se manifiestan sutilmente en palabras como exilio, migración, viaje, extranjería, nomadismo, distancia, deriva, etc. Con la lectura de Durmientes, podemos notar que en contraposición a la inestabilidad de encontrar una residencia (porque se estará "allá- afuera", siempre mirando hacia "aquíadentro"), la lengua y el arte se convertirán en los espacios donde pueden crecer las raíces; ante la pérdida, la escritura se torna en esa "casa recuperable", reinventada desde la memoria y el olvido.

Como se dijo anteriormente, el espacio biográfico apela a diversos géneros para construir el relato de una vida; la entrevista suele ser una excelente oportunidad para dar cuenta de las relaciones entre experiencia y arte, trasvasar el límite de lo público y lo privado, conocer la "trastienda de la creación" - 
en donde confluyen múltiples escenas de lecturas que acompañan el "trayecto" escriturario-, a partir de la que se construye también un mito de autor. Con motivo de la publicación de su última novela -Contralur- y ante la pregunta de la entrevistadora "¿Cómo se lleva con el lugar que nació?”, Sara Rosenberg ofrece un fragmento de su autobiografía:

"Amo y odio a Tucumán alternativamente con mucha rapidez; amo mi montaña, mi río, mi selva, los amigos que me faltan... Siempre sin darme cuenta estoy volviendo literariamente a Tucumán. Fue muy fuerte volver a Tucumán y encontrarme con todas las calles embanderadas con Bussi ${ }^{3}$, que fue votado. No entendía nada; para mí fue tan terrorífico que me fui rápidamente. Hasta que empecé a reconciliarme y me conecté con gente de la universidad. A los 17 años fui a parar a una cárcel de Tucumán, en 1970. Pasé tres años y medio sin juicio y fui amnistiada por Cámpora. Estaba en una agrupación universitaria y caí presa por un operativo, un robo a un banco. Cuando salí de la cárcel me quedé hasta el '75, pero estaba muy perseguida; empezaron a matar a todos los amnistiados. No tenía cómo sobrevivir. Me salvé porque un poco antes del golpe mi papá me pagó un pasaje a Montreal; después me fui a

\footnotetext{
${ }^{3}$ El 24 de marzo de 1976, Antonio Domingo Bussi se convirtió en interventor federal y jefe militar de Tucumán. En el período democrático fundó Fuerza Republicana (1988), partido que lo llevó a la gobernación y al Congreso Nacional. El voto le permitió ganar ocho elecciones; en 1993 asumió como diputado nacional y dos años después como gobernador de la provincia. En 1998, una Comisión Especial Investigadora reveló sus propiedades y depósitos bancarios, poco después se conocieron sus cuentas secretas, millonarias, en bancos de Suiza y Luxemburgo. En el primer juicio oral a los genocidas en Tucumán (2008), Bussi fue juzgado y condenado a prisión por violaciones de lesa humanidad; cumplió condena domiciliaria y murió en noviembre de 2011 ("Murió Antonio Domingo Bussi" en Página/12, 24/11/11). Disponible en http://www.pagina12.com.ar/diario/ultimas/20-181888-2011-11-24.html
} 
México porque ya no aguantaba otro invierno, yo soy un alma tropical (risas). De México me fui a España y ya no podía mover más a los chicos por tantos países... Hacíamos todo muy rápido, sentíamos que había poco tiempo y quemábamos etapas. Pero no me arrepiento de nada, fue el tiempo que me tocó vivir.” (Rosenberg, 2009)

Para la autora, el vínculo afectivo con el lugar de origen es conflictivo; los retornos al pago son numerosos, sucesivos y diferentes, cada regreso da cuenta del paso del tiempo (de los años transcurridos, de los cambios, etc.) y de las pérdidas irremediables. Con poder de síntesis, Sara Rosenberg narra algunos momentos cruciales de su vida como la militancia en la juventud, la experiencia carcelaria, la huida, las geografías y residencias continuas.

La experiencia del exilio es decisiva, no sólo en su trayectoria vital (como expresión de un "colectivo" o de una generación), sino también en su escritura: "El exilio siempre afecta. Nos cambia la vida y por lo tanto, la mirada. No es casual que Ulises le conteste al cíclope 'Mi nombre es Nadie"' (Rosenberg, 2007). El destierro es visto desde la singularidad de una vida, el quiebre que marca la expulsión y que rompe con los hábitos, con las rutinas, los rituales sociales de la familia y el trabajo, los espacios cotidianos, los afectos, etc.. Un poder demoledor que tiene su reverso: “...empezar a ser $\mathrm{Na}$ die. Empezar a nombrarte. A conocer. A desconocer. Y también a convivir con el dolor [...] Conocer, y aprender todo de vuelta es el aspecto positivo del exilio" (Rosenberg, 2007, p. 4). Frente al nomadismo -voluntario u obligatorio- la escritura permite el retorno; Luisa Valenzuela la define como un ancla, $N^{\circ} 2$. Segundo semestre de 2014 
"el lugar donde cuerpo y palabra se fusionan" (2009, p. 154). El exilio conjuga contradictoriamente lo traumático de la experiencia y la fuerza liberadora de la distancia:

"Hay un momento en que el exilio se convierte en viaje. Y la extranjería en un modo de vida. Las raíces se vuelven aéreas $[. .$.$] La no pertenencia permite una dis-$ tancia que también se va reflejando en el lenguaje, en la escritura." (Rosenberg, 2007, p. 5)

La diáspora permite conjugar un uso especulativo y especular de la distancia como operación creativa, como un procedimiento que complejiza la mirada y demanda oblicuamente la pertenencia (Negroni, 2006, p. 27). María Inés Cisterna Gold (2013) -en su estudio reciente Exilio en el espacio literario argentino de la postdictadura - advierte la presencia del destierro como síntoma de una tradición literaria argentina y propone leerlo como la contracara de una imagen de nación. El exilio conlleva una doble modulación: en sentido estricto, se refiere a una literatura de autores (la mayoría de ellos, expulsados) que trabajan el tópico del destierro; en sentido más amplio, abarca a toda la producción de autores exiliados (Cymerman, citado por Cisterna Gold, 2013). La pérdida se constituye en el eje central y funciona como disparador de estas escrituras que buscan llenar un vacío; en palabras de Rosenberg: "Sólo en la palabra hay tierra y sólo la palabra es casa” (2013, p.141). 


\section{Diario de viaje: las estaciones de la memoria}

El viaje adquiere dimensiones míticas en sus orígenes; las tradiciones grecolatina y judeocristiana nos han ofrecido arquetipos de viajeros que reaparecen en el tiempo como Odiseo/Ulises (figura con la que se identifica Rosenberg), que señalan un tipo de desplazamiento o traslado: el regreso del exilio. En pos de una claridad terminológica que nos permita identificar las vinculaciones posibles entre viaje y escritura, Sofía M. Carrizo Rueda (2008) distingue dos formas básicas: una, los "relatos de viaje" con la que nos referimos a la categoría de aquellos que escriben memorias que proporcionan información sobre el recorrido de ciertos territorios; y dos la "literatura de viaje", es decir obras de ficción que subordinan el itinerario a la existencia de sus personajes (2008, p. 9). Si bien los límites de ambas denominaciones están en estado de discusión, Carrizo Rueda propone pensar la segunda de ellas como "un género mixto en el que no se puede separar de ningún modo, lo documental de los recursos atribuidos a la literariedad" (2008, p. 11).

Podemos adscribir Durmientes al relato de viaje, puesto que se construye a partir de la mixtura de éste con el ensayo, la poesía, el diario, la crónica, la imagen, etc. Sin embargo, la idea del "viaje" estructura la narración; en este sentido, hacen falta algunas precisiones que pueden enriquecer la lectura. Luis Alburquerque García (2011) define el "relato de viaje" en base a tres criterios fundamentales: primero, éste se asienta en hechos, en la realidad, en los testimonios, en lo verificable, es un viaje concreto (p. 17) que puede ser sometido a un cierto grado de ficcionalización pero que remite a los componentes 
cronológico y topográfico, es decir, a un tiempo y a un espacio vivido por el viajero. Segundo, su discurso se detiene en la travesía, en los lugares y en todo lo circundante; tercero, se habla de lo que se ha vivido y recorrido, la cercanía del que narra revela su carácter parcial. El crítico agrega otros dos rasgos, la paratextualidad y la intertextualidad. Por un lado, la presencia de los paratextos ayudan a identificar el pacto de lectura que el texto propone: se trata de un viaje real. Así lo explicita una nota preliminar de Durmientes: "Escribí este libro -casi un diario- mientras hacía varios viajes en el tren de Tucumán-Buenos Aires; quería grabar un documental y pude hacerlo. Sin embargo nada como la lapicera para apuntar aquello que a través de la cámara se quedaba afuera" (Rosenberg, 2013, p.9). Se observa la marca de un "yo" que escribe y que ha viajado, un doble registro de la experiencia -la imagen audiovisual y el papel- y la distancia recorrida (medida en tiempo y en espacio). Por otro lado, la intertextualidad indica la puesta en diálogo con otros textos de la cultura, según Romero Tobar (citado por Alburquerque García, 2011) "los relatos de viaje se nutren de la experiencia real del viajero como de la escritura de relatos anteriores" que combina un "yo he visto" con "yo he leído", por lo tanto, el relato de viaje tiene un carácter bifronte (literario y documental) ${ }^{4}$ y articula un sujeto de doble experiencia (viaje y escritura). En términos de Mijaíl Bajtín, el relato de viaje puede ser definido como un género discursivo secundario que aloja en su interior a otros géneros primarios (Colombi, 2006, p. 13). Las “estaciones de la

${ }^{4}$ El documental Durmientes que da origen a la escritura de estos "apuntes de viaje" está disponible en https://www.youtube.com/watch?v $=\mathrm{H} 7 \mathrm{sBrhFmANU}$ o bien, http://www.crecerjuntos.org.ar/durmientes/. Consulta: 21/07/2014. 
memoria" conjugan las coordenadas de tiempo (las "estaciones" del año) y de espacio (las paradas del tren), Durmientes es un viaje y es, también, una travesía hacia el pasado del país. Como señala Colombi, detrás de todo relato de viaje, descubrimos una selección de momentos y escenas, una construcción jerarquizada de los sucesos y un reorde-namiento ideológico de todos los materiales; la mirada del viajero se convierte en protagonista (2006, p. 14).

Durmientes traza un itinerario lineal desde un punto de partida hasta el final del trayecto; sin embargo, el texto se dispersa en viñetas, corta el relato del viaje y se abre a múltiples temporalidades, a otros protagonistas, a otras geografías. El recuadro "Suiza en el río" funciona a modo de una equis que indica la salida: "El documental empieza aquí, con el sonido del río, desde los durmientes del agua a los durmientes del camino. Al final del horizonte, a la derecha, está la gran estación de Retiro, desde donde saldrá mañana mi tren hacia el norte" (Rosenberg, 2013, p. 28).

Mirar el río es parte del reconocimiento de una geografía sentida como propia, pero al mismo tiempo, "La historia reciente hace que el río sea un lugar amargo, un paisaje alterado por el dolor" (Rosenberg, 2013, p. 26); lugar atravesado por la violencia, "pesadilla inacabada" (p. 27), cuerpos desaparecidos, hundidos en el barro. Imagen de las ausencias que hieren la travesía hacia el otro lado del país; el imperativo de la memoria se hace presente, el tiempo no borra ninguna huella y deja el sabor agrio del olvido y la impunidad.

El tren se convierte en una reliquia, el extenso camino que dibujan las vías del ferrocarril narra el lado oscuro del 
presente:

"Los empleados y los ferroviarios, que conocí durante el viaje, fueron despedidos de un día para el otro, sin indemnización y sin cobrar siquiera el último sueldo trabajado.

La compañía NOA es privada, y el estado no intervino [...] La estación está cerrada. Mientras tanto, los trenes de carga siguen llevando toneladas de soja, trigo y minerales hacia el puerto de Rosario y de Buenos Aires...” (Rosenberg, 2013, p. 135)

Al contar las condiciones actuales del tren, la autora articula el presente con el pasado y despliega parte de la historia del ferrocarril, que funciona como sinécdoque del pasado nacional: "Vuelve el óxido. Los hierros viejos se anudan a la palabra deuda y debajo de la palabra deuda se esconde astutamente la palabra robo" (Rosenberg, 2013, p. 31). La autora denuncia la privatización de los vagones como parte de una política económica que extrae las riquezas del suelo argentino, lo llama "Ferrocidio" a partir de la lectura de Juan Carlos Cena, y es parte del "vaciamiento" sistemático que sufre el país y el continente latinoamericano, desde los tiempos de la conquista.

El libro de Rosenberg articula una "vista del pasado". El término acuñado por Émile Benveniste (1977) se refiere al "tiempo lingüístico" que entrama la vivencia humana del tiempo y tiene lugar a través del discurso, en presente (aquíahora). De esa manera, el acontecimiento queda situado en la contemporaneidad de la palabra: cuando el suceso ha dejado 
de ser simultáneo al discurso, deberá ser evocado por la memoria, en pasado. Beatriz Sarlo (2005) enfatiza el carácter constructivo de las "vistas del pasado", puesto que la irrupción del tiempo anterior "en el presente es comprensible en la medida en que se lo organice mediante los procedimientos de la narración, y por ellos, de una ideología que ponga de manifiesto un continuum significativo e interpretable de tiempo" (subrayado del original, p. 13).

En un breve recuadro intitulado "Ausencia", la vOz narradora se pregunta "¿Qué ha pasado, adónde se han ido, cómo se llama esta falta de lugar, quién arrasó lo que recuerdo bien, lo que existía?" y la respuesta es contundente, "Una ola gigante llamada saqueo", Rosenberg construye una vista del pasado nacional como genealogía del crimen: "Sólo es posible comprender este viaje que inicio, caminando sobre las huellas del pasado colonial, la política imperial y el llamado neoliberalismo" (2013, p. 60), robo histórico que extiende sus tentáculos hasta nuestros días: "Tengo la impresión de estar atravesando el paisaje de un país sitiado por dentro" (2013, p. 83). Aquel tren que unía el interior con la capital, y que supuso, antaño, una intensa movilidad migratoria, es ahora signo de empobrecimiento:

"El único tren de pasajeros es este, en el que voy. Sé que estoy haciendo un viaje en el tiempo. En mi memoria todo lo anterior tenía más vida que la que ahora veo: estaciones desiertas, pueblos abandonados, y una pobreza que lastima el corazón como dice bien el tango, y que resulta 
pornográfica, brutal, repugnante.” (Rosenberg, 2013, p. 93)

Estos apuntes de viaje articulan un doble funcionamiento, tanto como "lugares de la memoria" (Nora, 1998) como "trabajos de la memoria" (Jelin, 2002) ${ }^{5}$. La primera noción hace referencia a un inventario variado y extenso, de carácter simbólico y representativo de un pasado que se cristaliza desde un tiempo presente ${ }^{6}$; la segunda, señala a la memoria como un mecanismo cultural que tiene un papel altamente significativo en la configuración del pasado y la construcción de una pertenencia, los "trabajos de la memoria" supone pensar un lugar activo y productivo en los procesos de transformación simbólica y de elaboración de los sentidos del pasado (Jelin, 2002, p. 14); frente a la "inmovilidad" de los acontecimientos pretéritos que no pueden cambiarse, el "sentido" de ese pasado está sujeto a múltiples (re)interpretaciones- en pugna- ancladas a un tiempo presente y a las expectativas futuras (Jelin, 2002, p. 39). En este caso, Sara Rosenberg se autofigura como una transmisora de la memoria ${ }^{7}$, que desafía los olvidos por medio de su narración: "hablar, narrar, implica también resistir"

\footnotetext{
${ }^{5}$ La noción de Elizabeth Jelin es deudora de la propuesta de Pierre Nora. Ambas funcionan complementariamente, aunque impliquen distintos matices.

"Pierre Nora advierte que hablar de "lieu de mémoire" no se reduce a monumentos o a acontecimientos dignos de memoria, o a objetos puramente materiales, físicos, palpables, visibles, sino a la capacidad simbólica de cifrar en objetos, fórmulas e incluso palabras claves, una dimensión rememoradora de éstos (1998, p. 32).

${ }^{7}$ En su capítulo "El género en las memorias", Elizabeth Jelin señala los vínculos entre el sistema de género y la memoria; distingue, tanto dentro de la guerrilla como de la resistencia a la dictadura y la posterior reconstrucción democrática, a las mujeres como sujetos activos políticos, la presencia femenina en el movimiento de los derechos humanos como portadoras de la memoria social y, como narradoras, mediadoras y analistas de las memorias en el campo de la expresión pública, por medio de distintos géneros y manifestaciones (2002, p. 115). La producción de Sara Rosenberg puede ubicarse en este último grupo.
} 
(Rosenberg, 2007); el tren es una máquina memoriosa, que colecciona retazos del pasado individual y colectivo, la vida privada de la escritora se entrelaza a la historia de las ciudades y del territorio nacional que recorren los vagones, porque narrarla es una forma de trasmitir una experiencia, a partir de la clara conciencia de un estar situado "en la coordenada histórica y social que me determina” (Rosenberg, 2007).

Al cruzar la geografía hacia el norte, la viajera traza un mapa de los lugares de la memoria, "Con la red de mariposas que es el ojo de la cámara voy cazando temperaturas del desconcierto y formas del malestar. Es el relieve del territorio" (Rosenberg, 2013, p. 20); la memoria es afectiva -aclara Pierre Nora (1984)- y los lugares, en tanto, "restos" nacen y viven del sentimiento. La peregrina busca el nombre de lo que retrata (y rescata) con su cámara, interpreta la huella de lo que antes existía: "El verbo más frecuente es había. Aquí había". En este mismo sentido, la autora escribe un fragmento que señala otro momento de la travesía:

"Había una vez...", me dicen casi todas las personas que he ido encontrando en el viaje: "Aquí había", "Antes había", "Hubo", "Esto era", "Había un tiempo", "Había aquí...". Al escucharlos, empecé a darme cuenta que andaba caminando, viajando, sobre restos, y que cada resto emitía una luz propia..." (Rosenberg, 2013, p. 97)

Se observa que el "yo he visto" y el "yo he leído", que se mencionó anteriormente, se combina con el "yo escucho", puesto que Rosenberg recoge en su grabación los testimonios de pasajeros y maquinistas. Por otro lado, algunas palabras $N^{\circ}$ 2. Segundo semestre de 2014 
funcionan como claves rememorativas del pasado argentino y latinoamericano, por ejemplo, la viñeta "Cóndor" recupera los sentidos del plan homónimo de las dictaduras del Cono Sur, durante los años setenta, como parte de una misma historia:

“...el proyecto imperial estuvo dirigido básicamente a impedir que un cambio social tuviera alguna posibilidad de extenderse por América Latina. La lista de crímenes es enorme. Las dictaduras fueron una plaga, incluso tuvieron una sociedad anónima dedicada al exterminio de la oposición política [...] Se trataba de preservar un sistema social que, como se ve ahora claramente, no ha hecho más que destruir la industria nacional, los recursos naturales, la educación pública, el sistema de salud, las leyes sociales, las leyes básicas... la vida." (Rosenberg, 2013, p. 47)

La cita pone en evidencia la construcción narrativa de ese continuum entre el pasado y el presente que señala Beatriz Sarlo. Pero además, Rosenberg encuentra la clave de interpretación de la historia en aquellos "libros que los viajeros europeos escribieron sobre América", que manifiestan una "literatura extractiva" (2013, p. 47), dado que el continente es un botín destinado a ser poseído y conquistado. Otros textos como "Inglaterra" (2013, p. 33- 35), "Barbarie" (2013, p. 44), "In the most secret way" (2013, p. 57- 61) pueden leerse dentro de esta serie, cuyo eje es la destrucción de una economía estatal; el fragmento "Ferrocarril" concluye: "Todas las industrias que crecieron alrededor de las vías, desaparecieron también y el monte desierto es todo lo que veo, mientras avanzamos a veinte kilómetros por hora" (Rosenberg, 2013, p. 126). 
En este tejido memorioso, las escenas de lecturas aparecen como una modulación singular, no sólo porque éstas pueden leerse como marcas de lo biográfico ${ }^{8}$ (Arfuch, 2002), sino porque esos otros textos ingresan al caudal de la propia escritura de Rosenberg. Los libros cifran en sus palabras otro tipo de experiencias y se convierten en "casas portátiles" en la diáspora; autores como Roberto Fernández Retamar, Federico García Lorca, Juan José Hernández, Friedrich Hölderlin, César Vallejo, entre otros, forman parte de la biblioteca que se recuerda. Las lecturas nombran, explican o sintetizan las vivencias de la escritora migrante: el regreso a Buenos Aires, "nombre paradójico" para un "puerto pestilente, que se fue llenado de contrabandistas, miasmas y barriales" (Rosenberg, 2013, p. 23), la España fascista marcada a sangre con el silencio (p. 41), el cuento "Como si estuviéramos jugando" de otro tucumano desplazado (Hernández) que incorpora a su documental (p. 64), los versos de Hölderlin -"Vuelvo a mi tierra como a un jardín de difuntos" (p. 68)- que refuerza la idea de un retorno atravesado por las ausencias y que retumba en esos otros versos de Vallejo - "Hay golpes en la vida tan duros yo no sé..."- que le permiten decir a Rosenberg que "sobrevivir no fue fácil" (2013, p. 68).

Las nociones de "lugares" y "trabajos" de la memoria se articulan complementariamente, puesto que sobre estos materiales o palabras claves se pone de manifiesto una tarea activa de deconstrucción y reconstrucción de los sentidos por parte del sujeto que recuerda; una variación de esos trabajos memo-

\footnotetext{
${ }^{8}$ Es decir, "biografemas” (Arfuch, 2002, p. 123).
} 
riosos puede leerse en "Mendicidad", especie de relato incrustado dentro del viaje:

"Estuve recordando que en Tucumán la mendicidad también tuvo su historia particular. En 1966, cuando se produjo el golpe militar del general Onganía, se cerraron la mayoría de los ingenios azucareros, que eran la base del sistema económico de la provincia. Desde el siglo XVIII el azúcar fue el "oro blanco" de los terratenientes y de los dueños de ingenios. Los obreros que cortan la caña y los obreros industriales se quedaron sin trabajo, emigraron. Más de 250.000 personas se fueron a otras regiones del país y la ciudad se llenó de hambrientos, que debieron encontrar su lugar al lado de los tradicionales mendigos con sitio fijo, el "Loco Vera", "Cola de Chancho", o "Perlita", que se sentaban en la Plaza Independencia, en el Parque 9 de Julio, en la puerta de la Casa Histórica, o en la Iglesia de San Francisco, y que fueron monumentos vivos de nuestra infancia." (Rosenberg, 2013, p. 75).

Como sucede con los numerosos relatos que van engrosando las páginas de Durmientes, Rosenberg se pregunta sobre el binomio "ficción- historia" e indaga las labores de la memoria a la hora de narrar el pasado frente a una historia oficial que olvida. Nuevamente, la autora construye un relato que enfatiza los lazos del presente con un pasado. El "cerrojazo" (Pucci, 2007) de los ingenios azucareros, que significó la ruina económica de la principal industria de la 
provincia ${ }^{9}$, se vincula a sus orígenes latifundistas, a la lucha obrera popular que pasó a un primer plano (Nassif, 2011) y a estos marginales que circulaban por las calles céntricas de la ciudad capital de Tucumán. Rosenberg, junto a otros autores de la provincia como Carlos Alsina y Tomás Eloy Martínez ${ }^{10}$, recupera el mito urbano de estos personajes que signaron su infancia y la de su generación: "Tenían un halo de sabios urbanos, borrachos o magos. Nos acercábamos durante las tardes a escuchar sus cuentos, los discursos encendidos o las palabras incomprensibles que nos decían. La ciudad tenía un espacio para ellos..." (Rosenberg, 2013, p. 75). El dictador decidió limpiar la ciudad, tapió con chapas metálicas las villas y mandó cazar a los mendigos, fueron depositados en un camión y enviados a la frontera con Bolivia (o a Catamarca, según otras versiones). Muchos murieron en la travesía, de frío y de hambre. Muy pocos lograron regresar (Rosenberg, 2013, p. 75). En esos "otros", la autora encuentra una imagen especular de su propio destierro y supervivencia.

Durmientes es también la ruta hacia la infancia, la lengua y el cuerpo. El libro se repliega sobre los espacios públicos hacia los espacios de lo privado y lo íntimo; de esa manera, la narración construye un "ser íntimo" que se revela, solo en partes, al lector y ese rincón del yo se enlaza a la necesidad de dar nom-

\footnotetext{
${ }^{9}$ Para entender las profundas vinculaciones entre el cierre de los ingenios azucareros y los procesos sociopolíticos que sucedieron entre los años sesenta y los setenta, pueden consultarse La Cepa. Arqueología de una cultura aqucarera. Tomo I, II y III de Eduardo Rosenzvaig (1995-1999); El Tucumanazo de Emilio Crenzel (1998); Historia de la destrucción de una provincia. Tucumán 1966 de Roberto Pucci (2007) y Tucumanazos. Una huella histórica de luchas populares 1969-1972 de Silvia Nassif (2011).

10 Véase: Limpieza (1988) de Carlos Alsina; el artículo "La expulsión de los mendigos" (2004) de Tomás Eloy Martínez para La Nación y el reciente libro Los mendigos y el tirano (2011) de Pablo Calvo.
}

$N^{\circ} 2$. Segundo semestre de 2014 
bre, abandonarse a la avalancha de la lengua que es placentera: “...me sumerjo en el sonido [...] Es un gusto recuperar el sonido de la infancia, la lengua añorada, el silencio propio de cada gesto, y hasta el suspiro. Hay música en la lengua que es una manera de pensar. Una manera de estar en el mundo y de compartirlo." (Rosenberg, 2013, p. 30)

Tornar a su ciudad, a la que ama y rechaza, es por otro lado, regresar al origen, a la tierra, a la "Pachamama": “... vuelvo porque aquí sigue viviendo mi madre. Un cuerpo importante, la dueña del territorio epitelial" (Rosenberg, 2013, p. 62). El cuerpo, el de la madre y el propio, es el territorio primero de la existencia; a través de la carne, el hombre hace que el mundo sea la medida de su experiencia (Le Breton, 2002, p. 7). Junto con el cuerpo, se recuperan "viejas palabras botánicas y escolares, esporas, peciolado, cotiledóneas y monocotiledóneas, parásitas y epífictas, tarcos, lapachos, cedros, molles, cebiles, aromos dorados, jacarandas, palos borrachos, y cañas, mucha amarga caña de azúcar" (Rosenberg, 2013, p. 66). En el inventario de la lengua que yace oculta, algunas palabras tienen el poder de emerger con vida propia: "durmientes", que había permanecido sumergida, llega de la mano de otra lectura "El hombre duerme y sueña, se parece a un muerto. Cuando despierta se asemeja a un durmiente" dice Heráclito (subrayado del original, Rosenberg, 2013, p. 88). Nombre para el libro, para los amigos desaparecidos, para los cuerpos secuestrados y para sí misma: Sara Rosenberg es una "durmiente"/ sobreviviente de la última dictadura argentina. Por ello, aunque regrese una y mil veces, siempre sentirá que "soy extranjera" en mi propia tierra (p. 39). 


\section{Conclusiones}

Términos como heterogeneidad, cruce, hibridez, mixtura, desplazamiento, movimiento, errancia, frontera, entre otros, han atravesado nuestra propuesta de lectura de Durmientes. Apuntes de viaje. Con todos ellos, hemos intentado entender la producción de Sara Rosenberg que trabaja en los límites de los géneros y del arte. Junto a ese "nombre propio", se escribe la historia de una vida marcada por el exilio en un doble juego de exhibición y autojustificación -¿por qué no regresa? se preguntará el lector-y se dibujan las fronteras problemáticas entre estética y ética, entre geografías que invierten los valores de lo local y lo extranjero, entre arte y realidad. Durmientes, puede ser leído en ese puente entre ficción y verdad, en esa tensión entre identidad y narración, en esa dualidad que no permite la reducción de algunos de sus polos. Si bien no hemos más que enunciado el interrogante de "cuál es el lugar de Sara Rosenberg en el campo literario (y artístico, podríamos agregar) argentino", es posible por medio de la lectura de Durmientes arrojar algunas hipótesis futuras que abren el panorama: se trata de un lugar errante, que se construye en la paradoja del adentro/afuera. Gran parte de su producción literaria, dramatúrgica y artística permanece en el territorio de lo ignorado, puesto que sus libros, por ejemplo, tienen una circulación estrecha en la Argentina; de allí, que las ediciones cartoneras contribuyan a visibilizar, aunque más no sea, una porción de su narrativa.

En la entrevista que citamos más adelante, Sara Rosenberg aclara cuál es su posición frente al arte:

$\mathrm{El}$ arte, además de cautivar, tiene una función ética profun- 
da, un deseo de provocar pensamiento, interrogantes. Llamémosle, urgencia por cambiar el mundo. Urgencia por preservar la vida. La escritura no es más que una forma de situarse en este sentido, y una manera de crear el mundo que habitamos (2009).

Durmientes aparece como la punta del iceberg de su obra completa, regida por una idea heterónoma del arte que busca asir los restos de lo real, sin renunciar al compromiso como imperativo fundamental de su arte. 


\section{Bibliografía}

Amícola, J. (2007). Autobiografía como autofiguración. Estrategias discursivas del Yo y cuestiones de género. Rosario: Beatriz Viterbo Editora.

Arfuch, L. (2002). El espacio biográfico. Dilemas de la subjetividad contemporánea. Buenos Aires: Fondo de Cultura Económica.

Bajtín, M. (1989). Teoría y estética de la novela. Madrid: Taurus.

Benveniste, Emile (1977). Problemas de lingüistica general. Buenos Aires: Siglo XXI.

Carrizo Rueda, S. M. (2008). Escrituras del viaje. Construcción y recepción de "fragmentos de mundo". Buenos Aires: Biblos.

Cisterna Gold, María Inés (2013). Exilio en el espacio literario argentino de la postdictadura. Gran Bretaña: Tamesis.

García, L. A. (2011). "El 'relato de viajes': hitos y formas en la evolución del género". Revista de Literatura, 15-34.

Jelin, E. (2002). Los trabajos de la memoria. Buenos Aires : Siglo XXI.

Le Breton, D. (2002). La sociología del cuerpo. Buenos Aires: Nueva Visión.

Lejeune, Philippe (1994). El pacto autobiográfico y otros estudios. Madrid: Megazul-Endymion.

Molloy, S. (2006). Prólogo. En S. Molloy, Poéticas de la distancia. Adentro $y$ afuera de la literatura argentina (págs. 9-13). Buenos Aires: Norma.

Nassif, S. (2011). Tucumanazos. Una huella histórica de luchas populares 1969-1972. Tucumán: Departamento Publicaciones Filosofía y Letras.

Negroni, M. (2006). Ir volver/ de un adónde a un adónde. En S. 
Molloy, Poéticas de la distancia. Adentro y afuera de la literatura argentina (págs. 23-33). Buenos Aires: Norma.

Nora, P. (1998). La aventura de "Les Lieux de mémoire". Ayer, 1734.

Pucci, R. (2007). Historia de la destrucción de una provincia. Tucumán 1966. Buenos Aires: Ediciones Pago Chico.

Pozuelo Yvancos, J. M. (2006). "La frontera autobiográfica". De la autobiografía: teoría y estudios. España: Crítica pp. 9 69.

Rosenberg, S. (1 de Diciembre de 2007). Conversación con Sara Rosenberg. 4-8. (R. Miltrescientoskilómetros, Entrevistador)

Rosenberg, S. (Dirección). (2005). Documental Durmientes [Película].

Rosenberg, S. (2013). Durmientes. Apuntes de viaje. Tucumán: El Cruce Cartonero.

Rosenberg, S. (27 de Julio de 2009). Entrevista a Sara Rosenberg, autora de la novela Contraluz. 1. (S. Friera, Entrevistador)

Sarlo, Beatriz (2005). Tiempo pasado. Buenos Aires: Siglo XXI.

Scarano, L. (2007). Palabras en el cuerpo. Literatura y experiencia. Buenos Aires: Biblos.

Speranza, G. (2012) Atlas portátil de América Latina. Ficciones errantes. Buenos Aires: Anagrama.

Valenzuela, L. (2006). La mirada dual y el clavel del aire. En S. Molloy, Poéticas de la distancia. Adentro y afuera de la literatura argentina (págs. 115-128). Buenos Aires: Norma. 